\title{
Reproduksi, Fekunditas dan Lama Hidup Tiap Fase Perkembangan Plutella xylostella (Lepidoptera : Ypnomeutidae) pada Beberapa Jenis Tumbuhan Cruciferae
}

\author{
Nenet Susniahti ${ }^{{ }^{*}}$, Tarkus Suganda ${ }^{1}$, Sudarjat ${ }^{1}$, Danar Dono $^{1}$ dan Andhita Nadhirah ${ }^{2}$ \\ ${ }^{1}$ Departemen Hama dan Penyakit Tumbuhan, Fakultas Pertanian, Universitas Padjadjaran \\ ${ }^{2}$ Alumnus Program Studi Agroteknologi, Fakultas Pertanian, Universitas Padjadjaran \\ *Alamat korespondensi: nenet.susniahti@yahoo.com
}

\begin{abstract}
Reproduction, fecundity and period of each growth phase of Plutella xylostella on some species of crucifers
\end{abstract}

Plutella xylostella L. is one of major pests of cabbage (Brassica oleracea). P. xylostella, also known as diamondback moth, is an oligophagous with limited host only a crucifers. The pest often causes damage on the plant in the low to high altitude of the land. It is able to attack cabbage leaf from seedling to harvesting. An alternative controlling method that can be done is by using potential parasitoid, Diadegma semiclausum. Its application can be done using conservation technique through environment modification such as planting ornamental plants as parasitoid food source and alternative host for $P$. xylostella. The research aimed to find alternative host for $P$. xylostella. Experiment was conducted at greenhouse of Department Plant Pests and Disease, Faculty of Agriculture, Universitas Padjadjaran. Experiment was carried out by observation method using Randomized Blocked Design consisted of five treatments and four replications. The result demonstrated that Rorippa indica and Cardamine hirsuta were alternative host for P. xylostella. The average number of eggs laid on $R$. indica and $C$. hirsuta were 226.75 and 216.25 eggs, respectively. Survival rate of $P$. xylostella infested on $R$. indica was $32.50 \%$ whereas the survival rate of $P$. xylostella infested on $C$. hirsute was $28.75 \%$. It can be concluded that $P$. xylostella was able to spend its whole life cycle on both plants.

Keywords: Crucifers, Fecundity, Growth phase, $P$. xylostella, Reproduction

\begin{abstract}
ABSTRAK
Plutella xylostella L. merupakan salah satu hama utama kubis (Brassica oleracea). P. xylostella, juga dikenal sebagai Diamondback moth, yang bersifat oligofag dengan inang terbatas hanya pada tanaman kubis-kubisan. Hama ini sering menyebabkan kerusakan tanaman pada dataran rendah dan tinggi. Hama ini dapat menyerang pertanaman kubis pada saat bibit sampai panen. Sebuah metode pengendalian alternatif yang bisa dilakukan adalah dengan menggunakan parasitoid, Diadegma semiclausum. Penerapannya dapat dilakukan dengan menggunakan teknik konservasi melalui modifikasi lingkungan seperti menanam tanaman hias sebagai sumber pakan untuk parasitoid dan inang alternatif untuk $P$. xylostella. Penelitian ini bertujuan untuk menemukan inang alternative dari $P$. xylostella. Percobaan dilakukan di rumah kaca Departemen Hama dan Penyakit Tumbuhan, Fakultas Pertanian, Universitas Padjadjaran. Percobaan ini dilakukan dengan metode observasi menggunakan RancanganAcak Kelompok yang terdiri dari 4 perlakuan dengan 4 ulangan. Hasil penelitian menunjukkan bahwa Rorippa indica dan Cardamine hirsuta merupakan inang alternatif bagi $P$. xylostella. Rata-rata jumlah telur yang diletakan pada $R$. indica dan $C$. hirsuta adalah 226, 75 dan 216,25 butir. Kelulusan hidup P.xylostella yang di-infestasikan pada $R$.
\end{abstract}


indica adalah $32,50 \%$ dan pada $C$. hirsuta adalah $28,75 \%$. serta pada kedua jenis tanaman tersebut, P.xylostella dapat menyelesaikan seluruh siklus hidupnya.

Kata Kunci : Cruciferae, Fase perkembangan, Fekunditas, $P$. xylostella, Reproduksi

\section{PENDAHULUAN}

Tanaman kubis sampai saat ini masih menjadi salah satu komoditas hortikultura yang banyak dibudidayakan petani di Indonesia. Salah satu kendala dalam upaya peningkatan produksi kubis adalah serangan Organisme Pengganggu Tanaman (OPT). Hama ulat daun kubis P. xylostella L. (Lepidoptera : Yponomeutidae) merupakan salah satu hama penting yang sering menyerang tanaman kubis baik di dataran tinggi maupun dataran rendah.

P.xylostella tergolong serangga hama yang bersifat oligofag, yaitu berdasarkan sumber makanannya hanya menyerang jenis tanaman dari Famili Cruciferae (Pivnick, 1994). Ulat daun kubis dapat menyerang semua stadia tumbuh baik vegetatif maupun generatif. Serangga hama ini menyerang pucuk dan daun tanaman kubis mulai dari pembibitan hingga panen. Bagian tanaman yang diserangnya adalah daun dengan gejala berlubanglubang (Sastrosiswojo, 1987). Selain itu, tanaman budidaya dan gulma yang termasuk Famili Cruciferae dapat menjadi inang dari $P$. xylostella.

Menurut Kartosuwondo \& Sunjaya (1990), kuantitas dan kualitas senyawa primer maupun sekunder pada tumbuhan inang berpengaruh terhadap perkembangan dan ketertarikan P.xylostella pada berbagai jenis tumbuhan. Selain faktor makanan, pertumbuhan dan perkembangan serangga dipengaruhi pula oleh faktor abiotik. Kondisi suhu yang tinggi, menyebabkan populasi serangga meningkat, sebaliknya populasi akan menurun pada saat musim hujan (Sarjani, 2009).

Penelitian sebelumnya melaporkan bahwa rata-rata siklus hidup $P$. xylostella pada tanaman kubis adalah 15 hari pada kondisi $16^{\circ} \mathrm{C}-25^{\circ} \mathrm{C}$ (Permadi, 1993). Pada musim kemarau, kerusakan kubis akibat serangan hama $P$. xylostella dapat mencapai $100 \%$ dan jika populasinya tinggi dapat menyebabkan kematian tanaman karena daunnya habis dimakan, sehingga tinggal tulang daunnya saja (Sastrosiswojo dkk. 2005). Pengendalian yang dilakukan petani pada umumnya menggunakan insektisida sintetis. dan mempengaruhi perkembangan serta ketertarikan $P$. xylostella terhadap berbagai jenis tumbuhan.
Pengendalian hama dengan menggunakan insektisida sintetis umunya dinilai paling praktis dan hasilnya dapat langsung terlihat jelas (Julaily, dkk., 2013). Namun penggunaan insektisida yang terus menerus dan berlebihan dapat menimbulkan resistensi pada hama sasaran, serta permasalahan pencemaran lingkungan (Untung, 2006). Menurut Prabaningrum, dkk. (2013), P. xylostella termasuk jenis hama yang mudah resisten terhadap insektisida sintetis, bahkan telah menjadi resisten pula terhadap insektisida Bacillus thuringiensis.

Terkait halnya dengan permasalahan resistensi hama terhadap pestisida, pengendalian hama secara hayati, merupakan salah satu alternatif pengendalian serangga hama yang ramah lingkungan. Pengendalian hama secara hayati bertujuan untuk meningkatkan potensi serangga musuh alami dalam mengendalikan populasi serangga hama. Parasitoid Diadegma semiclausum telah dimanfaatkan di Indonesia terutama pada pertanaman kubis di dataran tinggi. $D$. semiclausum diintroduksi ke Indonesia dari Selandia Baru karena sangat berpotensi mengendalikan populasi P.xylostella sebesar $80 \%$. Satu ekor parasitoid dapat memparasitasi 117 ekor larva $P$. xylostella (Sastrosiswojo, dkk., 2005). Namun seringkali terjadi kendala dalam aplikasi pengendalian hayati yang diakibatkan oleh praktik bercocok tanam, terutama pemakaian insektisida sintetis sehingga peranan parasitoid sebagai agensia pengendalian hayati menjadi sangat menurun. Wardani \& Nazar ( 2005) menyatakan bahwa tingkat parasitisasi $D$. semiclausum (parasitoid larva) di daerah dataran tinggi Jawa Barat, hanya 15,8\%. Kasus yang sama, dijumpai pula di Sumatera Barat yaitu tingkat parasitisasi $D$. semiclausum di lahan kubis sangat berfluktuatif antara 58,0\% - 63,2\% (Mauliina \& Muflihayati, 2008). Hal ini terjadi dikarenakan pola tanam secara monokultur dan penggunaan insektisida secara intensif oleh petani sebanyak 2-3 kali dalam seminggu.

Peran parasitoid larva $D$. semiclausum sangat penting sehingga keberadaannya perlu ditingkatkan melalui teknik konservasi atau augmentasi. Konservasi merupakan upaya untuk melindungi dan meningkatkan populasi serangga musuh alami dengan cara memodifikasi lingkungan, 
misalnya menggunakan sistem tanam polikultur dengan menanam tanaman berbunga sebagai sumber pakan tambahan bagi musuh alami, serta melestarikan tumbuhan liar (gulma) berbunga yang dapat dijadikan sebagai inang alternatif. P. xylostella termasuk serangga hama yang bersifat oligofag, yaitu serangga yang hanya menyerang jenis tanaman dari satu famili, baik tanaman budidaya maupun tumbuhan liar (gulma) (Hendrival \& Khaidir, 2012). Hal ini dapat dimanfaatkan oleh petani untuk memanfaatkan gulma sebagai tanaman tumpang sari. Pada upaya konservasi musuh alami, perlu dipilih jenis tumbuhan yang merupakan inang alternatif $P$. xylostella dan dapat menarik kehadiran serangga musuh alaminya.

Kelulusan hidup serangga merupakan bagian dari aspek biologi yaitu dari fase telur sampai reproduksi (Sudibyo dkk., 2004). Bila serangga dapat menyelesaikan siklus hidupnya pada suatu tanaman, maka tanaman tersebut diduga dapat menjadi tanaman inangnya. Kajian mengenai reproduksi dan kelulusan hidup $P$. xylostella pada beberapa jenis gulma diharapkan dapat memperoleh jenis gulma yang menjadi inang alternatif sehingga dapat dimanfaatkan dalam upaya konservasi $D$. semiclausum. Penelitian ini bertujuan untuk mempelajari reproduksi, fekunditas dan lamanya mendapatkan tumbuhan inang alternatif bagi P.xylostella.

\section{METODE PENELITIAN}

Percobaan dilaksanakan di Rumah Kaca, Departemen Hama dan Penyakit Tanaman, Fakultas Pertanian, Universitas Padjadjaran (UNPAD). Metode percobaan menggunakan metode observasi dengan Rancangan Acak Kelompok (RAK) yang terdiri dari lima perlakuan dan diulang empat kali. Perlakuan yang digunakan adalah tumbuhan liar yang tumbuh di sekitar pertanaman kubis, yaitu : Cardamine hirsuta (Famili Cruciferae), Rorippa indica (Famili Cruciferae), Taraxacum officinale (Famili Asteraceae), Sonchus arvensis (Famili Asteraceae), Brassica olaracea (Famili Cruciferae). Pengamatan dilakukan terhadap reproduksi, fekunditas dan lamanya hidup setiap fase tiap perkembangan $P$. xylostella pada setiap jenis gulma.

\section{HASIL DAN PEMBAHASAN}

\section{Reproduksi $P$. xylostella}

Serangga herbivora akan memilih tanaman inang sebagai tempat bertelur, berlindung, sumber pakan serta berkembang biak. Banyaknya telur yang diletakkan ngengat $P$. xylostella dipengaruhi oleh jenis tumbuhan yang digunakan. Ngengat $P$. xylostella memilih tiga jenis tanaman yang termasuk Famili Cruciferae (Cardamine hirsuta, Rorippa indica, dan Brassica oleracea) sebagai tempat untuk meletakkan telurnya (Tabel 1). Menurut Sodiq (2009), serangga betina akan meletakkan telurnya pada tempat yang berdekatan dengan pakan larvanya. Oleh karena itu, banyaknya telur yang diletakan dapat menentukan apakah tanaman tersebut disukai atau tidak oleh serangga tertentu.

Tabel 1. Rata-rata Jumlah Telur (Reproduksi) $P$. xylostella.

\begin{tabular}{llc}
\hline No & Perlakuan & $\begin{array}{c}\text { Jumlah Telur } \\
(\bar{x})\end{array}$ \\
\hline 1 & C. hirsute & $216,25 \mathrm{~b}$ \\
2 & R. indica & $226,75 \mathrm{~b}$ \\
3 & T. officinale & $0,00 \mathrm{a}$ \\
4 & S. arvensis & $0,00 \mathrm{a}$ \\
5 & B. oleracea & $243,75 \mathrm{~b}$ \\
\hline Keterangan & Angka yang diikuti dengan huruf yang sama \\
& menunjukkan tidak berbeda nyata menurut Uji & Jarak Berganda Duncan pada taraf nyata 5\%.
\end{tabular}

Fekunditas (Kelulusan hidup) P. xylostella.

Berdasarkan hasil pada Tabel 2 diketahui bahwa rata-rata persentase kelulusan hidup $P$. xylostella untuk perlakuan pakan dengan gulma dari Famili Cruciferae lebih tinggi daripada Famili Asteraceae. Hal ini sesuai dengan pendapat Safraz (2008), bahwa $P$. xylostella tergolong serangga yang bersifat oligofag, dimana serangga hama hanya menyerang jenis tanaman dari Famili Cruciferae. Adapun larva yang diberi perlakuan pakan jenis gulma $S$. arvensis dari Famili Asteraceae hanya mampu bertahan hidup sampai instar ke-3 yaitu kelulusan hidupnya sebesar $3,75 \%$. Selain itu, larva $P$. xylostella yang diberi perlakuan pakan $T$. officinale, tidak dapat berkembang dan mati pada saat instar 1. Kondisi yang menyebabkan larva tidak mampu menjadi imago pada perlakuan pakan gulma dari Famili Asteraceae diduga karena kualitas dan kuantitas nutrisi yang terkandung dalam tumbuhan tidak sesuai atau tidak mencukupi bagi perkembangan larva $P$. xylostella. Hal ini didukung oleh pernyataan Ulmer et al. (2002) bahwa nutrisi pada tanaman dapat menentukan kualitas dan kuantitas makanan untuk menunjang proses fisiologi yang berkaitan dengan pertumbuhan dan perkembangan serangga. 
Tabel 2. Fekunditas (kelulusan hidup) P. xylostella.

\begin{tabular}{|c|c|c|c|c|c|c|}
\hline \multirow[b]{2}{*}{ Jenis inang } & \multicolumn{4}{|c|}{ Rata-rata banyaknya larva pada tiap instar $(\%) \pm \mathrm{SD}$} & \multirow[b]{2}{*}{ Pupa } & \multirow[b]{2}{*}{ Imago } \\
\hline & $\begin{array}{c}\text { Larva } \\
\text { Instar } 1\end{array}$ & $\begin{array}{c}\text { Larva } \\
\text { Instar } 2\end{array}$ & $\begin{array}{c}\text { Larva } \\
\text { Instar } 3\end{array}$ & $\begin{array}{c}\text { Larva } \\
\text { Instar } 4\end{array}$ & & \\
\hline C. hirsuta & $95,00 \pm 1,41 \mathrm{c}$ & $95,00 \pm 1,41 \mathrm{c}$ & $95,00 \pm 1,41 \mathrm{c}$ & $76,25 \pm 0,50 \mathrm{~b}$ & $60,00 \pm 1,83 \mathrm{bc}$ & $28,75 \pm 0,96 b$ \\
\hline$R$. indica & $86,25 \pm 0,96 c$ & $86,25 \pm 0,96 b$ & $86,25 \pm 0,50 b$ & $81,25 \pm 1,26 b$ & $52,50 \pm 0,58 b$ & $32,50 \pm 0,58 b$ \\
\hline T. officinale & $0,00 \pm 0,00 \mathrm{a}$ & $0,00 \pm 0,00 \mathrm{a}$ & $0,00 \pm 0,00 \mathrm{a}$ & $0,00 \pm 0,00 \mathrm{a}$ & $0,00 \pm 0,00 \mathrm{a}$ & $0,00 \pm 0,00 \mathrm{a}$ \\
\hline S. arvensis & $8,75 \pm 0,05 b$ & $6,25 \pm 0,50 \mathrm{a}$ & $3,75 \pm 0,50 \mathrm{a}$ & $0,00 \pm 0,00 \mathrm{a}$ & $0,00 \pm 0,00 \mathrm{a}$ & $0,00 \pm 0,00 \mathrm{a}$ \\
\hline B. oleracea & $88,75 \pm 1,50 \mathrm{c}$ & $82,50 \pm 1,29 b$ & $82,50 \pm 1,29 b$ & $82,50 \pm 1,29 \mathrm{~b}$ & $66,25 \pm 2,22 c$ & $62,50 \pm 1,29 c$ \\
\hline
\end{tabular}

\section{Lama Hidup Tiap Fase Perkembangan}

Berdasarkan hasil penelitian yang telah dilakukan, ternyata terdapat pengaruh yang sangat berbeda antara tumbuhan Cruciferae dengan Asteraceae terhadap lama hidup tiap fase perkembangan $P$. xylostella. Hal ini dikarenakan $P$. xylostella adalah serangga hama yang bersifat oligofag dan hanya memilih tumbuhan Cruciferae sebagai sumber makanannya.

Selain faktor makanan, suhu dan kelembaban dapat berpengaruh pula terhadap lama perkembangan $P$. xylostella. Hasil dari penelitian menunjukkan bahwa rata-rata lama fase larva yaitu
$12,75-13,38$ hari pada suhu berkisar $24^{\circ} \mathrm{C}-27^{\circ} \mathrm{C}$ dan kelembaban 67\% - 82\%. Menurut Permadi (1993), suhu dan kelembaban optimum untuk pertumbuhan dan perkembangan $P$. xylostella adalah $17^{\circ} \mathrm{C}-25^{\circ} \mathrm{C}$ dan kelembaban $60 \%$ - $90 \%$. Faktor suhu akan berpengaruh terhadap proses metabolisme serangga. Apabila suhu lingkungan naik, maka proses metabolisme semakin cepat, sehingga waktu yang dibutuhkan untuk menyelesaikan perkembangan serangga akan semakin cepat (Raihana, 1994), demikian pula sebaliknya.

Tabel 3. Rata-rata lama hidup tiap stadium perkembangan $P$. xylostella.

\begin{tabular}{lcccccc}
\hline Jenis inang & $\begin{array}{c}\text { Larva } \\
\text { Instar1 } \\
(\bar{x} \pm \mathrm{SD})\end{array}$ & $\begin{array}{c}\text { Larva } \\
\text { Instar } 2 \\
(\bar{x} \pm \mathrm{SD})\end{array}$ & $\begin{array}{c}\text { Larva } \\
\text { Instar } 3 \\
(\bar{x} \pm \mathrm{SD})\end{array}$ & $\begin{array}{c}\text { Larva } \\
\text { Instar } 4 \\
(\bar{x} \pm \mathrm{SD})\end{array}$ & $\begin{array}{c}\text { Pupa } \\
(\bar{x} \pm \mathrm{SD})\end{array}$ & $\begin{array}{c}\text { Imago } \\
(\bar{x} \pm \mathrm{SD})\end{array}$ \\
\hline C. hirsuta & $3,25 \pm 0,20 \mathrm{~b}$ & $3,08 \pm 0,11 \mathrm{~b}$ & $3,15 \pm 0,10 \mathrm{~b}$ & $3,51 \pm 0,07 \mathrm{~b}$ & $5,16 \pm 0,10 \mathrm{~b}$ & $13,60 \pm 0,18 \mathrm{~b}$ \\
R. indica & $3,37 \pm 0,36 \mathrm{~b}$ & $2,87 \pm 0,16 \mathrm{~b}$ & $3,76 \pm 0,15 \mathrm{~b}$ & $3,38 \pm 0,23 \mathrm{~b}$ & $5,19 \pm 0,18 \mathrm{~b}$ & $13,70 \pm 0,20 \mathrm{~b}$ \\
T. officinale & $0,00 \pm 0,00 \mathrm{a}$ & $0,00 \pm 0,00 \mathrm{a}$ & $0,00 \pm 0,00 \mathrm{a}$ & $0,00 \pm 0,00 \mathrm{a}$ & $0,00 \pm 0,00 \mathrm{a}$ & $0,00 \pm 0,00 \mathrm{a}$ \\
S.arvensis & $3,10 \pm 0,25 \mathrm{~b}$ & $4,25 \pm 0,50 \mathrm{c}$ & $2,50 \pm 1,73 \mathrm{~b}$ & $0,00 \pm 0,00 \mathrm{a}$ & $0,00 \pm 0,00 \mathrm{a}$ & $0,00 \pm 0,00 \mathrm{a}$ \\
B. oleracea & $3,32 \pm 0,28 \mathrm{~b}$ & $2,69 \pm 0,27 \mathrm{~b}$ & $3,30 \pm 0,45 \mathrm{~b}$ & $3,44 \pm 0,47 \mathrm{~b}$ & $5,23 \pm 0,14 \mathrm{~b}$ & $14,05 \pm 0,27 \mathrm{c}$ \\
\hline \multicolumn{7}{c}{ Keterangan : Angka yang diikuti dengan huruf yang sama menunjukkan tidak berbeda nyata menurut Uji Jarak Berganda Duncan } \\
pada taraf nyata 5\%.
\end{tabular}

Berdasarkan hasil analisa statistik, tumbuhan $C$. hirsuta dan $R$. indica, memberikan pengaruh yang sama dengan kubis $B$. oleracea terhadap banyaknya telur yang diletakan, kelulusan hidup, serta lama hidup fase larva dan pupa $P$. xylostella. Meskipun lamanya hidup fase imago yang diberi perlakuan pakan tumbuhan $C$. hirsuta dan $R$. indica lebih pendek dibandingkan dengan pakan $B$. oleracea, tetapi $P$. xylostella dapat menyelesaikan siklus hidupnya pada dua tanaman inang alternatif tersebut. Berdasarkan uraian diatas, maka tumbuhan $C$. hirsuta dan $R$. indica dapat dimanfaatkan sebagai tanaman campuran atau tumpangsari pada pertanaman kubis dalam upaya meningkatkan diversitas tanaman serta pengelolaan musuh alami di pertanaman kubis.

\section{SIMPULAN}

Berdasarkan hasil penelitian mengenai reproduksi, fekunditas dan lama hidup tiap fase perkembangan dari $P$. xylostella pada beberapa jenis gulma diketahui bahwa $R$. indica dan $C$. hirsuta dapat menjadi inang alternatif bagi serangga hama 
tersebut. Rata-rata jumlah telur yang diletakkan pada tanaman gulma $R$, indica dan $C$. hirsuta adalah sebanyak 226,75 dan 216,25 butir, secara berurutan. Selain itu dilaporkan pula bahwa $P$. xylostella dapat menyelesaikan siklus hidupnya pada kedua jenis tanaman gulma $R$. indica dan $C$. hirsuta.

\section{PUSTAKA}

Hendrival dan Khaidir. 2012. Toksisitas ekstrak daun Lantana Camara L. terhadap hama Plutella xylostella L. J. Floratek 7 : $45-56$.

Julaily, N, Murkalina dan TR Setyawati. 2013. Pengendalian hama pada tanaman sawi Brassica Juncea L. menggunakan ekstrak daun papaya Carica papaya L. J. Protobiont. 2 (3):171- 175.

Kartosuwondo, U, dan Sunjaya. 1990. Potential role of wild crucifers in the preservation of Diadegma eucerophaga Horstm. (Hymenoptera : Ichneumonidae), a parasitoid of Diamondback-moth, Plutella xylostella Linn. (Lepidoptera: Plutellidae). Biotropika 4: 31 - 40.

Maulina, F, dan Muflihayati. 2013. Conservation of Diadegma semiclausum Hellen. parasitoids as biological control to Plutella xylostella Linn. with adult food exploration. International Journal on Advanced Science Engineering Information Technology 3 (5) : $6-8$.

Pivnick, KA, JJ Blair, and GP Slater. 1994. Identification of olfactory cues used in host plant finding by diamondback moth,
Plutella xylostella (Lepidoptera: Plutellidae). J. Chem.Ecol. 20: 1407 - 1427.

Permadi, AH. 1993. Kubis. Badan Penelitian dan Pengembangan Pertanian. Balai Penelitian Hortikultura, Lembang. 155 hal

Prabaningrum, L, TS Uhan, U Nurwahidah, Karmin, dan A Hendra. 2013. Resistensi Plutella xylostella terhadap insektisida yang umum digunakan oleh petani kubis. di Sulawesi Selatan. Jurnal Hortikultura 23 (2): 164 173.

Safraz, M, LM Dosdall, and BA Keddie. 2008. Host plant genotype of the herbivore Plutella xylostella (Lepidoptera : Plutellidae) affects the performance of its parasitoid Diadegma insulare (Hymenoptera: Ichneumonidae). Biol. Control. 44 (1): 42-51.

Sastrosiswojo, S, TS Uhan, dan R Sutarya. 2005. Penerapan teknologi PHT pada tanaman kubis. Balai Penelitian Tanaman Sayuran. 55 hal.

Sudibyo, F, Andriansyah, Budianto, CT Astari dan LM Aritonang. 2004. Pengaruh ekstrak etanolik daun tempuyung (Sonchus arvensis L) in-vitro terhadap aktivitas glutation stransferase pada beberapa organ Rattus norvegius galur sprague-dawley. Biologi 3 (4): $231-242$.

Ulmer, B, C Gillot, D Woods, and M Erlandson. 2002. Diamondback moth, Plutella xylostella L. feeding and oviposition preferences on glossy and waxy Brassica rapa L. lines. Crop Protection 21: 327-331. 